\title{
О ПОДХОДАХ К РАЗРАБОТКЕ ДОРОЖНОЙ КАРТЫ РАЗВИТИЯ ИНСТИТУТОВ ИНТЕГРАЦИИ В РЕГИОНАЛЬНЫХ МЕЖГОСУДАРСТВЕННЫХ ОБЪЕДИНЕНИЯХ СТРАН С РАЗВИВАЮЩИМИСЯ РЫНКАМИ
}

\author{
(c) 2019 Сунь Юймэн \\ стажер кафедры Экономической теории и менеджмента \\ Московский педагогический государственный университет, Россия, Москва \\ E-mail: chairt.etm@bk.ru \\ (C) 2019 Платонова Елена Дмитриевна \\ доктор экономических наук, профессор, \\ заведующий кафедрой Экономической теории и менеджмента \\ Московский педагогический государственный университет, Россия, Москва \\ E-mail: ed.platonova@mpgu.edu
}

В статье раскрываются теоретико-методологические и методические подходы к разработке дорожной карты развития институтов интеграции на примере Шанхайской организации сотрудничества (ШОС). Данная дорожная карта рассматривается как стратегический инструмент планирования и институционального проектирования. Выделены этапы эволюции и приоритетные институты интеграции, приоритетные сферы развития институтов интеграции ШОС.

Ключевые слова: интеграция, институты интеграции, дорожные карты развития институтов интеграции, комплексная дорожная карта развития институтов интеграции; этапы развития институтов интеграции; типы институтов интеграции; Шанхайская организация сотрудничества.

Одной из основных выявленных современными исследователями закономерностей развития мировой экономики выступает глобализация, воздействие которой на функционирование национально-государственных экономических систем носит неоднозначный характер. С одной стороны, начиная с периода распада социалистической системы хозяйства в последней декаде 20 века, утверждаются рыночные механизмы функционирования национальных экономик, а рыночные принципы хозяйствования стали носить глобальный характер, объединяя мировую экономику, за исключением Северной Кореи. С другой стороны, ускорились процессы создания региональных интеграционных экономических образований (союзов, группировок, объединений, партнерств и др.). Так, в настоящий период Всемирная торговая организация (ВТО) насчитывает 301 региональное торговое соглашение, составляющих экономическую основу региональных образований. При этом, в 2009 г. ВТО декларировало только 201 соглашение, а в 1999 г. -72 соглашения [11, с. 21].

Несмотря на наличие достаточно большого массива публикаций, в современных исследованиях региональных межгосударственных объе- динений не уделяется должного внимания изучению институтов интеграции, которые должны «скреплять» экономику стран, входящих в региональные объединения стран с развивающимися рынками, в том числе, с участием Китая и России, обеспечивая поэтапный процесс экономической интеграции.

В этой связи особый научный интерес вызывают теоретико-методологические и методические подходы к разработке дорожной карты развития институтов интеграции (ДКРИИ) на уровне региональных межгосударственных объединений стран с развивающимся рынками. В данном контексте под дорожной картой понимается стратегический инструмент планирования и институционального проектирования, в котором определяется, как целевую направленность институциональных усилий государствучастников интеграционного образования, так и желаемый результат развития формальных и неформальных институтов интеграции, который достигается на определенных временных отрезках в доступном для планирования горизонте (средне- и долгосрочном).

Одним из основных преимуществ разработки дорожной карты, как инструментария разви- 
тия институционального контура межгосударственной экономической интеграции, является возможность концентрации усилий и ресурсов на определенных странами-участницами стратегических направлений развития институтов интеграции, как институтов их взаимодействия на экономическом пространстве, а также определения ключевых приоритетов данного эволюционного процесса.

В настоящее время в условиях глобальной турбулентности, возрождения элементов протекционизма и санкционного давления наиболее актуальной задачей выступает разработка ДКРИИ на экономическом пространстве Шанхайской организации сотрудничества (ШОС), в котором активную роль играют Китай и Россия.

Образованная в 2001 году, ШОС является постоянно действующей межправительственной международной организацией, которая прошла значительную дистанцию по пути обретения черт интеграционного объединения с формирующимися формальными и неформальными институтами интеграции экономического пространства. Несмотря на то, что в Хартии ШОС (2002) терминологически понятие «интеграция» применяется в контексте координации подходов государств при интеграции в мировую экономику, в данном программном документе в качестве основного направления сотрудничества в рамках ШОС зафиксирована «поддержка и поощрение регионального экономического сотрудничества в различных формах, содействие созданию благоприятных условий для торговли и инвестиций в целях постепенного осуществления свободного передвижения товаров, капиталов, услуг и технологий» [14]. Это свидетельствует о том, что создание общего рынка, как одного из закономерных и необходимых этапов прохождения по «лестнице интеграции» (Б. Баласса) было предусмотрено при рождении ШОС. Однако, как это следует из положений «Стратегии развития Шанхайской организации сотрудничества до 2025 года», в обозначенном плановом горизонте ШОС не предусматривает формирование экономического интеграционного объединения с образованием наднациональных институтов управления [12].

В теоретическо-методологическом аспекте зафиксированный подход к вопросу об образовании наднациональных институтов управления, как разновидности институтов интеграции, в региональных группировках созвучен с пози- цией представителей концепции функционализма, которые не разделяли точку зрения об их необходимости (Д. Митрани и др.) [1].

При разработке ДКИИ ШОС необходимо выделять методический подход, который активно разрабатываются зарубежными и отечественными экономистами применительно к различным сферам, секторам и сегментам современной экономики. Данные разработки охватывают, прежде всего, стратегически важные элементы национальных экономических систем [5], [9].

С методической точки зрения при разработке ДКРИИ следует определить временной отрезок, для которого разрабатывается дорожная карта и приоритетные типы институтов интеграции, стратегическое развитие которых позволит перейти к качественно новому этапу развития институтов интеграции ШОС. Из данного положения вытекает тот факт, что рамках разработки ДКРИИ возникает потребность в определении актуального этапа развития институтов интеграции ШОС, а также проведение различий между этапами эволюции институтов интеграции со неопределенным временным горизонтом и вполне конкретным прогнозным периодом реализации ДКРИИ ШОС.

Выделим наиболее общие этапы эволюции институтов интеграции, во время которых происходят процессы трансформации содержания и изменения самой конфигурации институтов интеграции. Приведем краткую характеристику следующих этапов: начальный этап, в течение которого формируются и «достраиваются» институты интеграции; второй этап - этап гармонизации национальных институтов и институтов интеграции; третий этап - этап развития институтов интеграции «на собственной основе» и формирования наднациональных институтов регулирования процессов в экономическом пространстве региональных образований; четвертый этап - этап трансформации экономического суверенитета стран-участниц регионального объединения и передача всех ключевых экономических функций наднациональным институтам интеграции.

Применительно к сегодняшнему состоянию процессов институализации межгосударственных экономических отношений в ШОС можно констатировать, что институты интеграции в экономическом пространстве ШОС находятся на первом этапе своей эволюции. Вместе с тем, с связи с расширением стран «шанхайской семьи» 
целесообразно теоретически обосновать существование особого стартового временного периода институтагенеза во вновь присоединившихся странах-членах ШОС, когда в них создаются условия для зарождения институтов интеграции. При этом зарождающиеся в этих условиях институты интеграции следует относить по терминологии, предложенной Г.Б. Клейнером, к протоинститутам, которые фиксируют появление в институциональной структуре национальногосударственной системы экономических субъектов, как инициирующих создание институтов интеграции, так и содействующих интеграции (прозелитов, пропагандистов, дистрибьютеров) [4]. Кроме того, с учетом наличия в «семье» ШОС стран с различным статусом целесообразно, по нашему мнению, отражение в дорожной карте «мягких форм» интеграции и имплементирование «интеграционной стратегии ассоциированного развития» для стран-партнеров по диалогу и наблюдателей [10, с. 7]. Закономерно, что такая стратегия предусматривает сохранение значительной самостоятельности формальных институтов интеграции в периоде их зарождения в рамках национально-государственных систем стран-участниц в решении интеграционных вопросов.

В современных институциональных построениях практически не представлен классификационный подход к институтам интеграции региональных межгосударственных экономических образований. Однако исследователями институциональной структуры экономики, исходя из концептуального положения о разнообразии и многообразии институтов, выделены различные критерии классификации и соответствующие им группы и типы институтов (А. Аузан, В. Вольчик, Д. Норт, Г. Клейнер, И. Киянов и другие). Формирование институтов интеграции региональных образований стран с развивающимися рынками следует рассматривать, по нашему мнению, как инновационный процесс, поскольку в экономической истории этой группы стран такой прецедент отсутствует. В этой связи возникает концептуальный вопрос, поставленный российскими экономистами (Г.Б. Клейнер, В.М. Полтерович и др.), о возможности заимствования (трансплантации) институциональной конструкции не одно десятилетие эволюционно развивающихся интеграционных региональных объединений, например, Европейского Союза (EC) [6].
В целом результативное движение этого регионального экономического объединения ряда стран Европы по «лестнице интеграции» может привести исследователей к обоснованию возможности заимствования основных институтов ЕС другими странами в силу их универсального характера. Последнее утверждение выступает своеобразным методологическим основанием для копирования опыта создания экономической структуры ЕС и ее институтов.

Не отрицая плодотворности исследования эволюции основных институтов интеграции ЕС, включая этапы и целевые функции на каждом их них, следует отметить, что нами не разделяется точка зрения о том, что институты интеграции, функционирующие в ЕС, носят универсальный характер и возможен прямой перенос институциональной структуры ЕС в другие региональные группировки.

В историко-генетическом аспекте интегрирующиеся страны имеют собственный «культурный и ментальный код», который оказывают решающее воздействие, прежде всего, на неформальные институты интеграции. Это исключает их копирование и возможность разработки ДКИИ ШОС как реплики пройденного ЕС и другими региональными экономическими образованиями пути институционального развития. Действительно, «копирование (калькирование) социально-экономических моделей как успешных для конкретных стран является ... тупиковой ветвью в движении общества» [7, с. 205].

Скептическое отношение к возможности копирования системы институтов интеграции EC не означает, что отрицается научная и практическая ценность результатов анализа опыта формирования и функционирования институтов интеграции данного регионального союза. Напротив, лучшие зарубежные практики позволяют глубже понять сферу их действия, избежать рисков дисфункций таких институтов.

Данное положение имеет особое значение при разработке ДКРИИ ШОС, поскольку при создании этой структуры изначально декларировались принципы «шанхайского духа», которые опираются на такие неформальные институты, как институты взаимного доверия, добрососедства, равноправия, уважения многообразия культур, дружбы, справедливости и другие ценностно-ориентированные институты межгосударственных отношений между странами «шанхайской семьи» [12]. Однако желание стран- 
участниц, как объектов и субъектов интеграционного взаимодействия, опереться на данные неформальные институты не означает, что на первом этапе эволюции ШОС они уже сформированы и эффективно функционируют.

Институциональные изменения в социокультурной сфере интеграционного образования, сокращение культурного расстояния при сохранении культурных и исторических национальных традиций, адаптация ментальных основ экономической деятельности населения в многонациональной и многоконфессиональной среде ШОС является важнейшем направлением ДКРИИ, как инструмента имплементации общей стратегии развития межгосударственного образования ШОС.

Опираясь на теоретические результаты работ институционалистов, а также интеграционную практику нами обоснована классификация институтов интеграции [8, с. 82-85]. Согласно данной классификации к институтам интеграции регионального межгосударственного объединения ШОС относятся формальные институты взаимодействия экономических агентов стран-участниц ШОС, среди которых необходимо выделить, во-первых, институты воздействия на экономических агентов, оперирующих в внутренней и внешней среде интеграционного образования (институты права; рынка; конкуренции; контрактов; государственной и межстрановой координации и регулирования; финансов; коммуникации; стандартизации, технического регулирования и др.); во-вторых, институты содействия (инноваций и технологий; промышленной кооперации; торгового сотрудничества; собственности, включая интеллектуальную; государственно-частного партнерства; иностранных инвестиций; предпринимательства; развития человеческого потенциала; гарантий, стимулов и преференций; государственных закупок; особых экономических зон; приграничного партнерства; информационного обеспечения; логистики и др.); в-третьих, институты противодействия деструктивным явлениям и процессам во внутренней и внешней среде интеграционного образования, а также дисфункциям институтов (институты нейтрализации и элиминирования экономических противоречий между странами-участниками ШОС, институты преодоления последствий мирового финансово-экономического кризиса; антимонопольного и экологического регулирования; экономической безопасности; нейтрализации нелегального и теневого бизнеса; элиминирования негативных последствий глобализации и др.); в-четвертых, институты сопряжения институциональных усилий (с правилами ВТО и подписанными странами «семьи ШОС» договорами на двух- и многосторонней основе; по согласованию интеграционных процессов в ЕАЭС, АТЭС и ШОС; по координации амбициозного инвестиционно-логистического проекта КНР «Один пояс - один путь» с экономическими и геополитическими интересами стран «семьи» ШОС и др.).

Расширительный подход к классификации институтов интеграции, как институтов взаимодействия экономических агентов в интеграционной среде региональных образований, обеспечивает, с одной стороны, их предельно широкий охват, но, с другой стороны, разработку дорожных карт развития каждого из представленных институтов интеграции. В этой связи целесообразна постановка вопроса о комплексной ДКРИИ как совокупности дорожных карт развития ряда приоритетных институтов воздействия, содействия, противодействия и сопряжения, сформированных и функционирующих в перспективных и приоритетных секторах экономического пространства ШОС. В «Стратегии развития Шанхайской организации сотрудничества до 2025 года» и других документах ШОС к таким секторам относятся торговая, производственная, энергетическая, транспортная, инвестиционно-инновационная, финансовая, сельскохозяйственная, таможенная, телекоммуникационная и технологическая (в частности, в области искусственного интеллекта) [12].

При разработке комплексной ДКРИИ необходимо определять не только ресурсы, позволяющие просчитать эффективность от мероприятий, включенных в ее разделы. Важно при определении всех параметров комплексной ДКРИИ (цель, результат, приоритеты, временной горизонт, механизм реализации) просчитывать геополитические и геоэкономические риски, поскольку «ситуация в глобальной политике и экономике остается турбулентной и напряженной, процесс экономической глобализации сталкивается с ростом односторонних протекционистских мер и других вызовов в международной торговле» [2].

Недооценка данных факторов, а также роли институтов противодействия может привести к тому, что разработанная комплексная ДКРИИ 
для определенного временного отрезка поэтапной эволюции институтов интеграции не будет реализована на практике. Примером того, как разработанные дорожные карты не были реализованы в полной мере, служат дорожные карты четырёх общих пространств, утвержденные высшими должностными лицами на Саммите Россия-ЕС в мае 2005 года [13].

Анализ теоретико-методологических и методических подходов к разработке ДКРИИ показал, что дорожные карты выступают инструментом стратегического планирования с определенным временным горизонтом, который может не со- впадать с этапами эволюции институтов интеграции в региональных интеграционных образованиях.

В настоящее время разработка комплексной ДКРИИ ШОС должна быть направлена на ускоренное решение задач по развитию институтов интеграции в рамках завершения первого этапа их формирования и эволюционный переход ко второму этапу развития институтов интеграции при повышении их качественных характеристик и усилению роли в обеспечении конкурентоспособности стран, входящих в «семью» ШОС.

\section{Библиографический список}

1. Бу Тун. Теоретико-методологические подходы к исследованию создания и развития интеграционных региональных экономических объединений государств (конец 40-х - начало 90-х годов 20 века) //Вестник Алтайской академии экономики и права. 2019. № 7 (часть 2) C. 22-32. URL: http://vaael.ru/ru/article/ view?id=646 (дата обращения 12.12.2019)

2. Бишкекская декларация Совета глав государств - членов Шанхайской организации сотрудничества. 14 июня 2019 г. URL: http://www.kremlin.ru/supplement/5421(дата обращения 12.12.2019)

3. Декларация глав государств-членов Шанхайской организации сотрудничества о построении региона долгосрочного мира и совместного процветания. Пекин, 6-7 июня 2012 года. URL: http://www.kremlin.ru/ supplement/1232/print (дата обращения 14.12.2019)

4. Клейнер Г.Б. Институциональные изменения: селекция, проектирование или протезирование? URL: kleiner.ru/pubs/institutsionalnyie-izmeneniya-selektsiya-proektirovanie-ili-protezirovanie/(дата обращения 10.12.2019)

5. Лучинкин М.Ю. Дорожная карта развития информационного общества в России// Информационное общество. 2008. № 1-2. С. 25-36.

6. Постсоветский институционализм. Под ред. Р.М. Нуреева, В.В. Дементьева. Донецк: «Каштан», 2005.- 480 c.

7. Платонова Е.Д. Современная теория и практика накопления (трансформационный аспект) / Под ред.д.э.н., проф. Е.В. Юферевой. М.: Изд-во АПКиППРО, 2006-367 с.

8. Платонова Е.Д., Сунь Юймэн. Классификация и этапы развития институтов интеграции в современных мегарегионах//Пространственная экономика: проблемы региональных экономических объединений. Материалы XV Международной научной конференции Россия, Москва, 23 июня 2017 г.- Москва: Издательство «Перо», 2018.- $101 \mathrm{c}$.

9. Пучков Л.А., Каледина Н.О. Разработка стратегии развития угольной отрасли на основе «дорожной карты»// Уголь. 2009. № 1 (993). С. 11-14.

10. Руденко M.Н. Методология формирования и развития стратегий интеграции предпринимательских структур в условиях постиндустриальной экономики. Автореф.... д-ра экон. наук. СПб.2015. 32 с.

11. Сунь Юймэн, Платонова Е.Д. Перспективы развития институтов интеграции в экономическом пространстве стран с развивающимися рынками//Экономические науки, 2019, № 10.с.20-26

12. Стратегия развития Шанхайской организации сотрудничества до 2025 года. 6-7 июня 2012 года, Пекин. URL: static.kremlin.ru/media/events/files/ru/a3YPpGqLvQI4uaMX431MkrMbFNewBneO.pdf (дата обращения 02.12.2019)

13. Саммит Россия - Евросоюз (Москва, 10 мая 2005 г.) Подписание дорожных карт четырех общих пространств//Современная Европа. 2005. № 3 (23). С. 124-155.

14. Хартия Шанхайской организации сотрудничества. URL: http://www.kremlin.ru/supplement/3450 (дата обращения 02.12.2019) 